Article

\title{
Using Scenarios to Assess Policy Mixes for Resource Efficiency and Eco-Innovation in Different Fiscal Policy Frameworks
}

\author{
Laurent Bontoux * and Daniel Bengtsson \\ European Commission Joint Research Centre, Brussels B-1049, Belgium; daniel.bengtsson@outlook.com \\ * Correspondence: laurent.bontoux@ec.europa.eu; Tel.: +32-2-299-1363 \\ Academic Editors: Francesca Montevecchi, Martin Hirschnitz-Garbers, Tomas Ekvall, Martha Bicket \\ and Patrick ten Brink \\ Received: 21 January 2016; Accepted: 23 March 2016; Published: 26 March 2016
}

\begin{abstract}
There is no longer any doubt that the European Union needs to manage a transition towards a sustainable economy and society. The complexity of such an enterprise is creating major challenges that require a future oriented systemic approach, looking at the EU economy and society as a whole, and going beyond current agendas and policies. The purpose of the JRC foresight study "2035: Paths towards a sustainable EU economy" was to explore how this could be possible. Resource efficiency was at the core of the reflection. This created a context where the fiscal framework was perceived by the experts involved as essential in driving (or hindering) the evolution towards a more sustainable future. Societal values (individualistic or collaborative) were selected as the other axis around which to construct four scenarios. A large number of other drivers of change were taken into account to construct scenarios of a sufficient depth and detail to generate a systemic understanding. The scenarios were used in an original way to help experts identify which policy mixes would be best adapted to push each scenario towards a more sustainable future, while respecting its own logic and constraints. For each scenario, 6 policy domains considered the most relevant were selected among more than 50. Research and innovation, new business models and education were considered important for all four scenarios. The other domains were natural resources management, regulation, ethics, employment, transparency, governance, social protection, and systems integration. The study illustrates how powerful a policy framework which is fiscally supportive of environmental sustainability can be in supporting resource efficiency and that this can be achieved in very different ways depending on the prevailing social values. It also shows how a combination of actions in other policy areas can be used to drive sustainability further. In sum, this work illustrates how the creative use of foresight can help design policy mixes that can open the way to very different paths towards a sustainable future.
\end{abstract}

Keywords: foresight; scenarios; sustainability; policy mixes; systemic approach; eco-innovation; resource efficiency

\section{Introduction}

There is no longer any doubt that the European Union needs to manage a transition towards a sustainable economy and society. The recent COP 21 has shown that the policy making world is aware of the need for this transition away from fossil fuels and that the size of the challenge is large. The adoption of its conclusions, after much haggling, signals that the political will to embark on the bold actions that are needed might be on the uptick. Two main obstacles can probably explain the remaining reluctance to implement this change. One is possibly a fear of cost and a lack of clear visions for new business opportunities in a low carbon world by the large corporate actors with the most 
political clout. Another is probably the very wide range and complexity of the simultaneous changes needed to make this happen. A potentially scary prospect.

Indeed, the complexity of such an enterprise is creating major decision-making challenges. This requires a new approach which is:

- future-oriented, as the necessary changes will take time to implement and will have to fit within a long-term vision;

- $\quad$ systemic, looking at the EU economy and society as a whole to ensure coherence of action; and

- $\quad$ acting across policy fields and going beyond current agendas and policies.

The purpose of this paper is to demonstrate a practical application of foresight in support of policy-making for complex issues. It shows how a proven methodology can be combined with a systematic consideration of relevant policy areas in a novel way to construct a long-term systemic reflection for addressing complex and far ranging issues such as sustainable transition. After discussing the choice of method and describing how the scenarios were developed, the paper presents how the discussions on the policy packages were organized and managed. The paper then gives some limitations of the approach and concludes on considerations to engage people beyond the study participants.

\section{Choice of Method}

Foresight has long been used for policy making. However, practice often falls into two main cases. Too often, foresight processes fail to involve policy-makers, making it necessary to find (more or less successful) ways to bring the results to where they should be useful. In the other cases, foresight is well established and embedded in the policy-making process. However, in these cases, its application is often focused on narrow objectives such as priority-setting, delivering recommendations for future research (e.g., on critical technologies), on delivering insights for disaster preparedness, or on supporting strategy development in the perspective of a clear objective. [1]. The authors are not aware of cases where foresight was used to develop systemic reflections on comprehensive alternative sets of policies to address potentially profound societal transformations, as would be the case for the sustainable transition. Over the last 20 years, the concept of 'sustainable transition' has been explored from many perspectives. Definitions vary but they all recognize that a sustainable transition requires dealing with complex socio-technical systems. Such systems consist of (networks of) actors (e.g., individuals, firms, and other organizations) and rules (e.g., societal norms, technical standards, regulations, and good practices), as well as material artifacts and knowledge [2].

Among foresight methods, scenario building is particularly well suited to provide valuable insights to help address this type of challenge. Recently, the JRC has performed a scenario-based foresight study to reflect on the transition towards a sustainable EU economy at the horizon 2035 [3]. By making a diverse group of experts think together on such a broad issue, scenario development facilitates systemic thinking, a pre-requisite for analyzing broad policy frameworks.

The study mobilized approximately 40 experts from very diverse backgrounds, ages, and geographical origins, most with a long experience in issues related to sustainable development. By engaging this unique group of concerned people to reflect collectively on what it would take to bring each 2035 scenario as close as possible to sustainability, this study embarked on policy mix thinking. Participants were coming from academia, the consulting world, the European Commission, industry, students, national ministries, business, national agencies, the Chinese Academy of Sciences, private foundations, the Club of Rome, policy think tanks, etc. Running the process in five workshops over more than one year provided a depth of analysis and detail in the scenarios that is not found commonly. Crucially, this also allowed the participants to reach a high level of common understanding that turned out to be essential when developing the sets of policies described below.

The study followed on and complemented previous work that focused on illustrating possible future sustainable lifestyles [4]. While the previous work illustrated people's daily lives in a sustainable 
future and defined objectives in terms of reduction in ultimate resource use per person, it did not address how this could be achieved. This study addressed how different industry, economy, and governance structures could shape the sustainability of lifestyles in the EU.

\section{Defining a Meaningful System to Study}

Eco-industries have been defined elsewhere [5,6], usually as industries whose objective is to reduce pollution or protect the environment. However, in view of the systems perspective taken by the foresight study, this usual definition was perceived as too narrow. The discussion on system definition in the study provided a multiple angle approach to "eco-industries" and generated many interesting exchanges between experts. Different perspectives came to the fore. Overall, there was a general realization of the complexity of the challenge of drawing simultaneously a broad and clear picture of the system to study.

Ultimately, "eco-industries" were seen as covering three lines of activities:

- "green industries" - the traditional environmental industries such as water management, waste-water treatment, soil and groundwater remediation, biomass composting, waste management, reuse, recycling, etc.;

- "industry greening" - the traditional industries as users/consumers of green innovation;

- "eco-innovative solution providers"-R\&D providers that provide others with "green" solutions, people who develop and apply new business models promoting resource efficiency, organizational/social innovators for sustainability, etc.

This description of "eco-industries" as a broad concept not only allowed the participants in the study to understand clearly enough what we were talking about, but also to engage in a systemic reflection about the evolution of our industrial economies towards more sustainability.

\section{Developing Scenarios}

Once this concept of "eco-industries" had been developed and taken on board by the expert panel of the study, we embarked on a classic scenario building process [7]. People were asked to identify which parameters (the drivers of change) would be expected to drive its evolution. Once this collection of drivers of change had been checked for completeness and coherence, the study participants engaged in a two-stage prioritization process: The drivers of change whose evolution was perceived as being the most uncertain were singled out. People were then asked to assess which ones they felt would have the highest potential impact.

Among this list of uncertain drivers of change, the two that ended up perceived as having the most potential impact were used as axes to create four scenarios in a $2 \times 2$ matrix. They were societal values and fiscal framework. The two extremes selected for the societal values axis were "collaborative society" and "individualistic society." For the fiscal framework axis, they were "not supporting sustainability" and "highly supporting sustainability." Each quadrant of the matrix was used to create a unique scenario describing the state in 2035 of a possible a transition towards a more sustainable future for the EU. The scenarios were developed so as to maximize diversity of perspectives. The four worlds resulting from this exercise were named: Multiple Connected Initiatives (Scenario 1), Shared Circular Strategies (Scenario 2), Compact Green Innovation (Scenario 3), and Local Self-Reliance (Scenario 4). Figure 1 presents the basic scenario logic. 


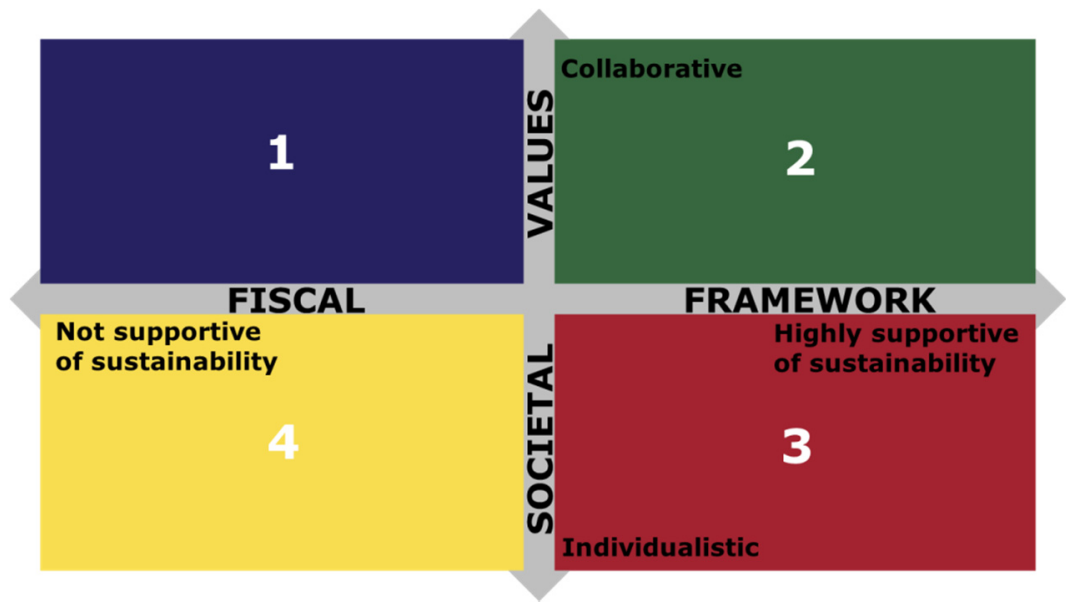

Figure 1. Scenario logic from the JRC foresight study 2035: Paths towards a Sustainable EU Economy.

Underlying all scenarios, a set of very likely drivers of change (megatrends) was analyzed with respect to their likely impact by 2035 . They are presented below:

"By 2035, the population of the world will probably reach 8.6 billion, with a stable ageing population in Europe but strong growth in Africa and parts of Asia. As the situation in emerging economies will also continue to improve, the global consuming class is expected to increase by 4 billion people, resulting in a strong demand for raw materials and energy. The first generation of "digital natives," with its new approach to social contacts and mastery of digital technologies, will be in power. Global warming could very well reach $2{ }^{\circ} \mathrm{C}$, with the accompanying rise in sea level and damage to agriculture and infrastructures. Urbanization will also continue unabated, leading to mega cities in the developing world and to more mid-sized cities in Europe. All this will happen in the context of continuing technological development (ICT, biotechnologies, materials, mobile technologies, sensors, etc.) that will lead to a hyperconnected world."

Here is a brief summary of the four scenarios.

"Scenario 1 (Multiple Connected Initiatives) depicts a rather flat and networked society. European society has shifted from competitive to more collaborative values. Informed and empowered citizens self-organize through globally connected local initiatives. Social networks play a key role in supporting direct democracy. The sense of collective identity extends to the global village, but co-operation within Europe remains predominant for addressing societal challenges. Disenchanted by centralized policy institutions and strongly connected by social media, a vibrant, informed, and empowered civil society takes the lead in addressing societal, economic, and environmental challenges. In this context, local authorities and Euro-regions raise their profile versus higher levels of government. They accompany this societal movement because they are often the first port of call for people engaged in initiatives to improve things they are confronted with locally. They provide platforms for people who want to collaborate but do not know how to. As a result, they start to engage through innovative policy-making and new funding mechanisms. Local authorities also make bridges between groups who are either not communicating or are in competition or disagreement.

Scenario 2 (Shared Circular Strategies) describes a world in which a strong collaborative ethos has emerged as a consequence of traumas created by catastrophic climate change. Society wants to survive. Solidarity mechanisms are strong and preoccupation with sustainability has generated a lot of social innovation that, in turn, has transformed European societies radically. In this top-down world, public authorities invest in large infrastructure projects for sustainable development. Integration of systems across society and the economy has made Europe very resource-efficient. 
Industrial symbioses are the norm. Here, the local level is not so much a source of initiatives but more a level of implementation for grand, EU-wide plans. However, the overarching objectives are adapted to local specificities to fit well in the diverse European local contexts.

Scenario 3 (Compact Green Innovation) is mostly characterized by individualism, frugality, and technological development. It is driven by the market. Mechanisms of social solidarity weaken. As creative and dynamic hubs, European cities are at the heart of new societal trends. However, they follow sometimes diverse development paths. Many become the focal point of the regions surrounding them regardless of national borders. Diverse geo-climatic conditions, historical legacies, and visions implemented by their managers create very different local dynamics. Some cities manage to create successful sustainable paths for development and are very attractive, whereas others fail to overcome adverse conditions and decline. The affluent manage to move to more successful cities, reinforcing negative trends in real estate prices in declining cities and price rises in the successful ones. This creates issues of social equity in a context in which centralized modes of governance become weaker.

Scenario 4 (Local Self-Reliance) describes an individualistic world in which governance at EU and national levels is weak and powerful interest groups have created niches of influence. This gives more room to local levels of government. As average income levels have fallen, social protection systems have been eroded, and the middle class has shrunk. Under external pressures, macroeconomic governance has become more integrated at EU level. The erosion of social protection systems also chipped away at citizens' respect for the "State." People consider that they have to rely on themselves more, with the result that they feel they need government less. Inequalities increase and powerful ICT platforms make direct democracy (and self-help) increasingly attractive, keeping governments in check but giving a greater role to the levels of government that are perceived to be closer, such as city and regional authorities. These have their hands full with managing disputes between self-centered citizens who want to have it all their own way. Many people may have a global outlook on the state of the environment but they care more about their own well-being and their own immediate environment than their country, Europe, or people further afield. It is a "live and let live," pragmatic, and flexible society in which private interests dominate."

A more extensive summary of the scenarios is available [8].

\section{Using the Scenarios for Policy-Making}

As this foresight study was performed in a perspective of support to policy making, one expert workshop was dedicated to reflect on what the scenarios could mean for policies at EU level.

Figure 2 illustrates schematically how one could see where each scenario would be in 2035 on their road towards a truly sustainable future.

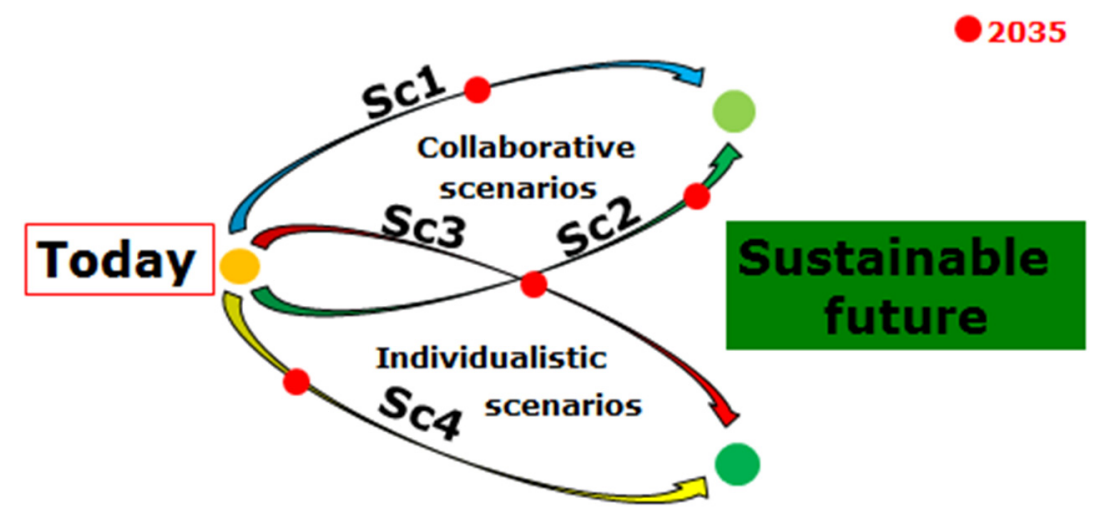

Figure 2. Relative positioning of the four scenarios in 2035 on their paths towards sustainability (red dots). 
On that basis, the collective systemic understanding generated during scenario development was used to reflect on what sets of policies could be applied to the four possible worlds in 2035 . The idea was to address the question: "What policies would one have to use today to bring each of the four scenarios as close as possible to sustainability?"

The first stage of that reflection consisted in a collective brainstorming to identify all policy areas that could be relevant (see Figure 3). This exercise was organized around four main chapters: society, technology, economy, and environment.

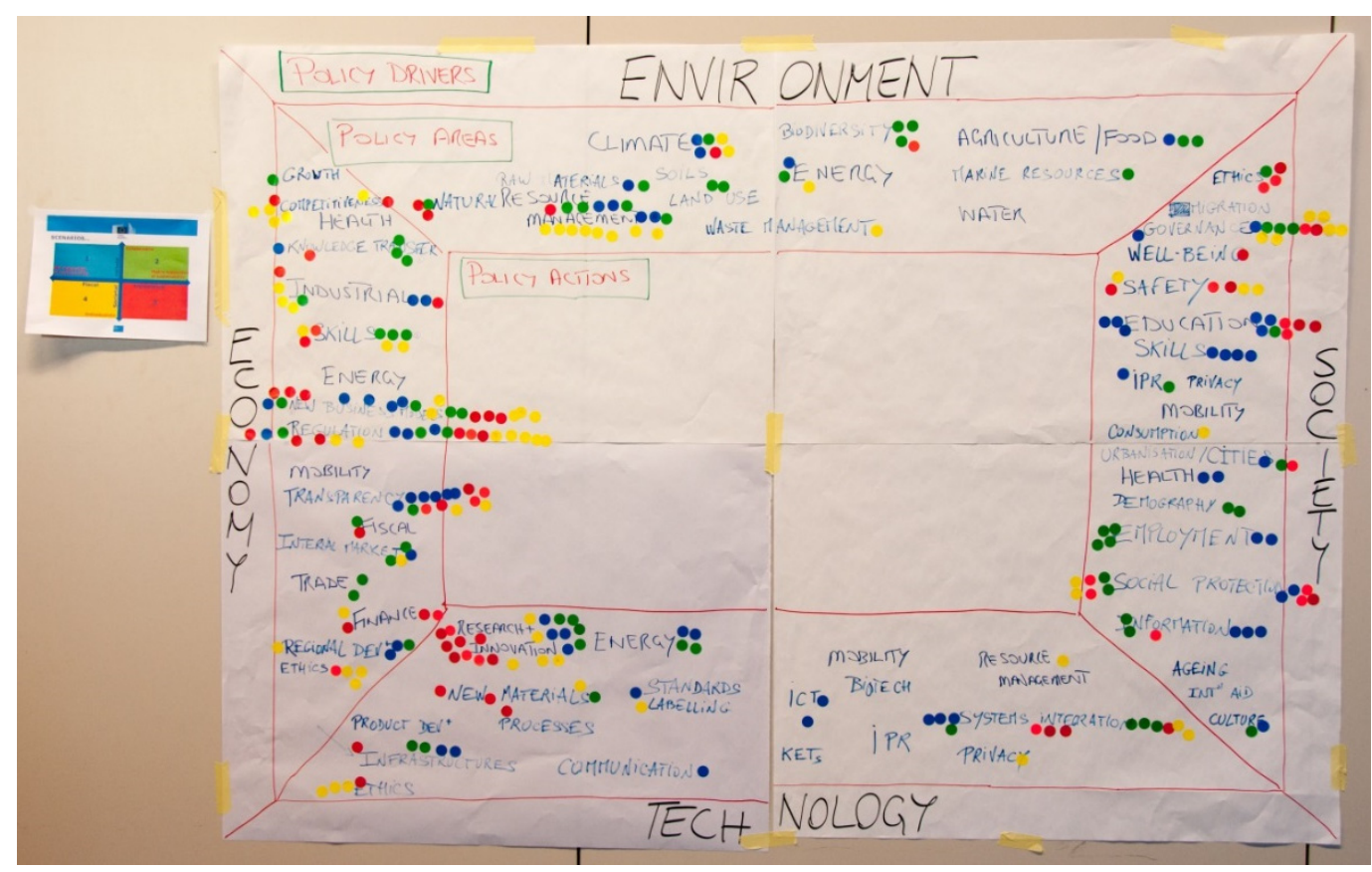

Figure 3. Identification of all the potentially relevant policy areas.

In view of the large number of potentially relevant policy areas identified, it was necessary to focus attention on the domains likely to be most important for each scenario. All participants were therefore given adhesive dots that were color-coded according to the scenarios ( 1 blue, 2 green, 3 red, and 4 yellow). They were then asked, for each scenario, to attribute their dots to the three policy areas they considered as the most important to bring the scenario further towards sustainability. In effect, in this step, we asked the participants to identify which policies would be most effective in addressing the scenario-specific barriers on the path towards sustainability. The results of this prioritization are shown in Figure 4.

After the prioritization, the number of policy areas deemed to be of significance was reduced to 17. Those appearing as the most significant were quite obvious: regulatory policy, natural resources management, research and innovation, new business models, and education. The last three appeared as important for all scenarios.

In order to go beyond the obvious and to develop policy approaches that would be specific enough, it was decided to develop six policy areas for each scenario (seven in the case of scenario 4). Table 1 gives the overview of which policy areas were developed for all scenarios.

The exercise was not meant to compensate for the intrinsic attributes of the scenarios, but to reflect on the full potential of selected policies to foster sustainability within the constraints created by the logic of each scenario. 


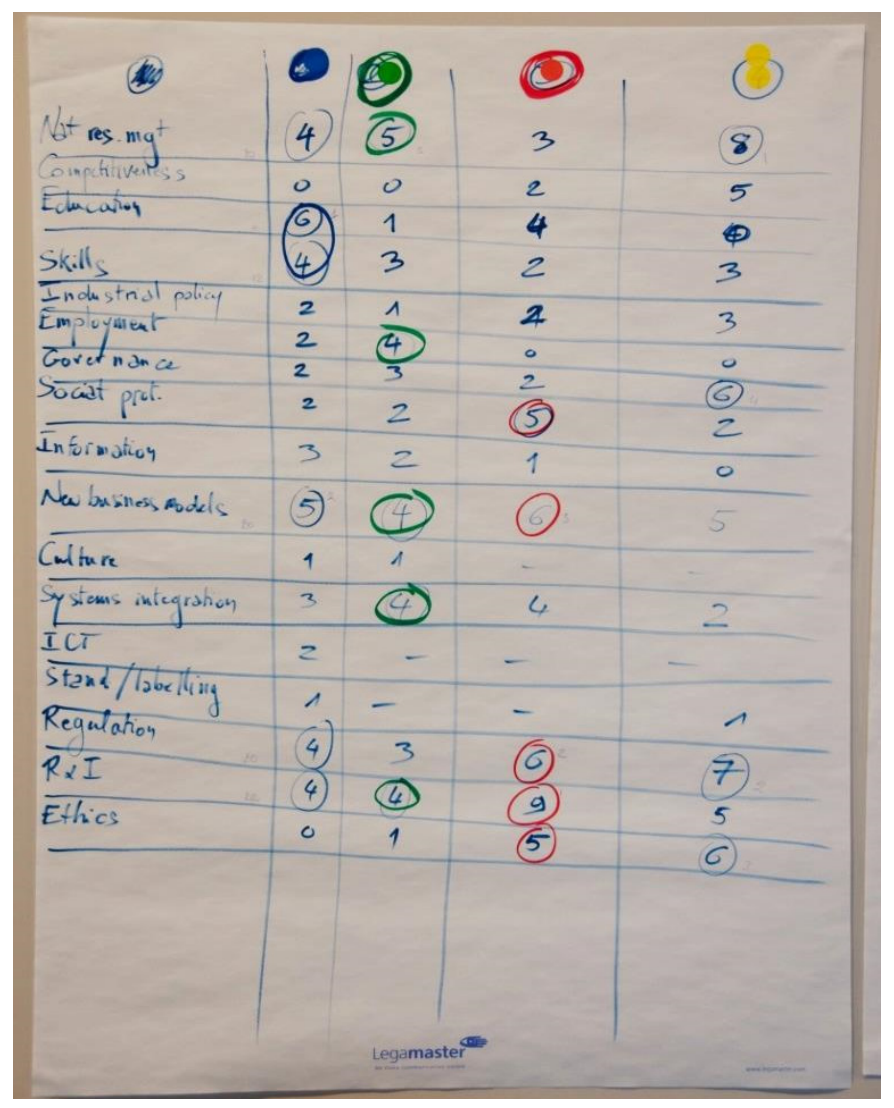

Figure 4. Prioritization of the policy domains per scenario.

Table 1. Policy areas discussed and explored for each of the 4 scenarios.

\begin{tabular}{ccccc}
\hline Policy issues & Scenario 1 & Scenario 2 & Scenario 3 & Scenario 4 \\
\hline Scenario Titles & $\begin{array}{c}\text { Connected } \\
\text { Initiatives }\end{array}$ & $\begin{array}{c}\text { Shared Circular } \\
\text { Strategies }\end{array}$ & $\begin{array}{c}\text { Compact Green } \\
\text { Innovation }\end{array}$ & $\begin{array}{c}\text { Local } \\
\text { Self-Reliance }\end{array}$ \\
\hline Research and Innovation & $\mathrm{X}$ & $\mathrm{X}$ & $\mathrm{X}$ & $\mathrm{X}$ \\
Natural Resources Management & $\mathrm{X}$ & $\mathrm{X}$ & $\mathrm{X}$ & $\mathrm{X}$ \\
New Business Models & $\mathrm{X}$ & $\mathrm{X}$ & $\mathrm{X}$ & $\mathrm{X}$ \\
Regulation & $\mathrm{X}$ & $\mathrm{X}$ & $\mathrm{X}$ \\
Education & $\mathrm{X}$ & & $\mathrm{X}$ \\
Ethics & $\mathrm{X}$ & & & $\mathrm{X}$ \\
Employment & & & & \\
Transparency & & $\mathrm{X}$ & \\
Governance & & & & \\
Social Protection & & & & \\
\hline
\end{tabular}

\section{The Policy Recommendations as Policy Packages}

As the whole study took a systemic thinking approach from the start, the systemic perspective of the policy areas to be explored was obvious to the participants. Once the policy areas most relevant for each scenario had been identified, their substance was developed according to a common template covering rationale, objective, challenges, actors/stakeholders, and targets. The objective of this template was to lead participants to think in terms of specifics and to deliver concrete ideas.

The way the question was framed ("What policies would one have to use today to bring each of the four scenarios as close as possible to sustainability?"), using the word "policies" instead of "policy," and 
applying the question to whole scenarios, also stimulated people to take a broad range of aspects into account together in a systemic fashion. Even if the participants were not explicitly asked to consider the policies as "packages," when reflecting on the policies necessary to reach the objective, they considered naturally the connections and coherence between them within each scenario. Additionally, the members of the study team moderating the work of the experts in groups per scenario also made sure that the discussions remained in the logic of each scenario. All policy areas were discussed in one single discussion, which reinforced the common framing of all policy considerations.

The next objectives were to make the discussions as concrete as possible and to reinforce consistency in the discussions across scenarios and policy areas. In view of the nature of the study, the objective of this exercise was to remain at the level of the "basic policy package" as defined by the SPREE project [9]. For this, the project team used a template. For all policy areas, five sections had to be addressed: rationale for the policy intervention, specific objective, challenges likely to be encountered, actors and stakeholders concerned, and possible targets to assess success of the policy intervention (See Figure 5). If the exercise were to be performed "for real," it would be possible to continue the reflection and engage in developing effective policy packages (looking at possible contradictions and unintended effects) and viable policy packages (including political feasibility) [9].

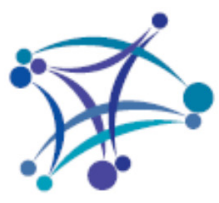

\section{SCENARIO 1}

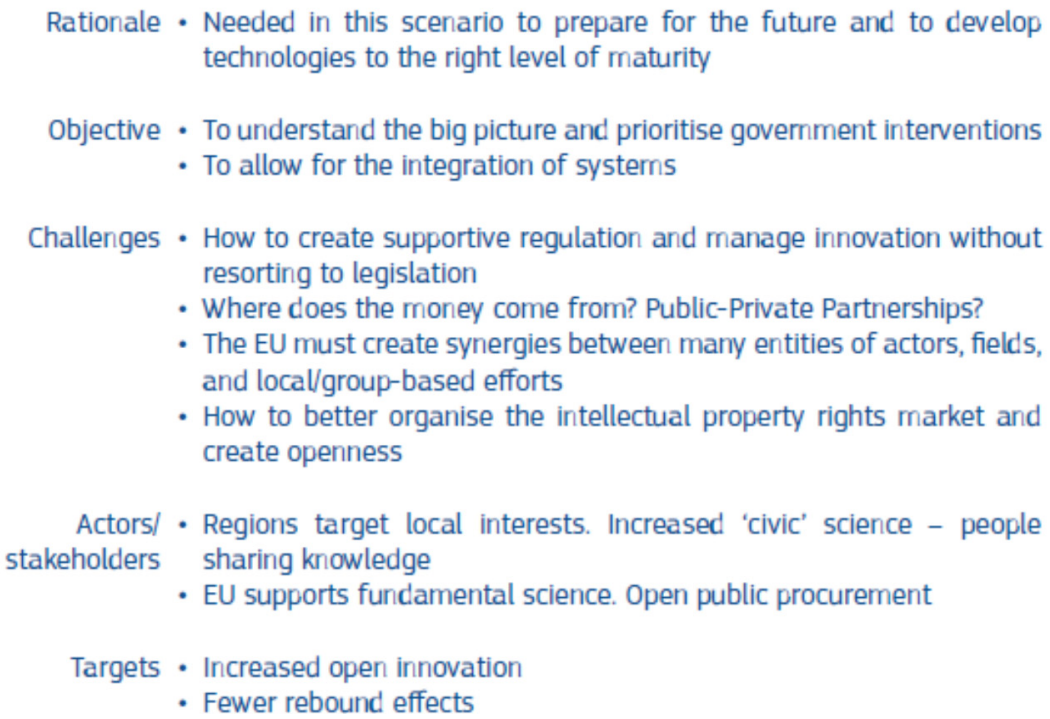

Figure 5. Example of a worked out policy area (Research and Innovation in Scenario 1).

There is no space here to get into a detailed analysis of all the policy mixes developed for all four scenarios to promote the evolution towards a more sustainable future under different conditions. The reader can consult the full report of the foresight study [3] to access all details. However, two main general lessons can be drawn on the approach.

In the cases where the same policy area was developed in different scenarios, the scenarios allowed the study participants to develop scenario-specific rationales and objectives for policy action, as illustrated by Figures 5 and 6 . This shows the usefulness of scenarios as frames to develop concrete conversations on policy packages.

In the case where a specific scenario was used to put the discussions on several policy areas into perspective, the process ensured a strong level of coherence across them all. This broke silo thinking and made it possible to talk truly of conversations around "policy packages."

However, in view of the generic nature of the scenarios and of the broad question to address, there was a limit to the level of specificity that could be reached by performing this exercise. In addition, 
while the exercise made sense to the participants in the study because they had reached a high level of common understanding through the foresight process, communicating the logic developed in the study to people who are not familiar with it could be a challenge. Therefore, the issue emerged of how the results of this study could be used to derive more specific ideas and recommendations and how to engage with a broad public.

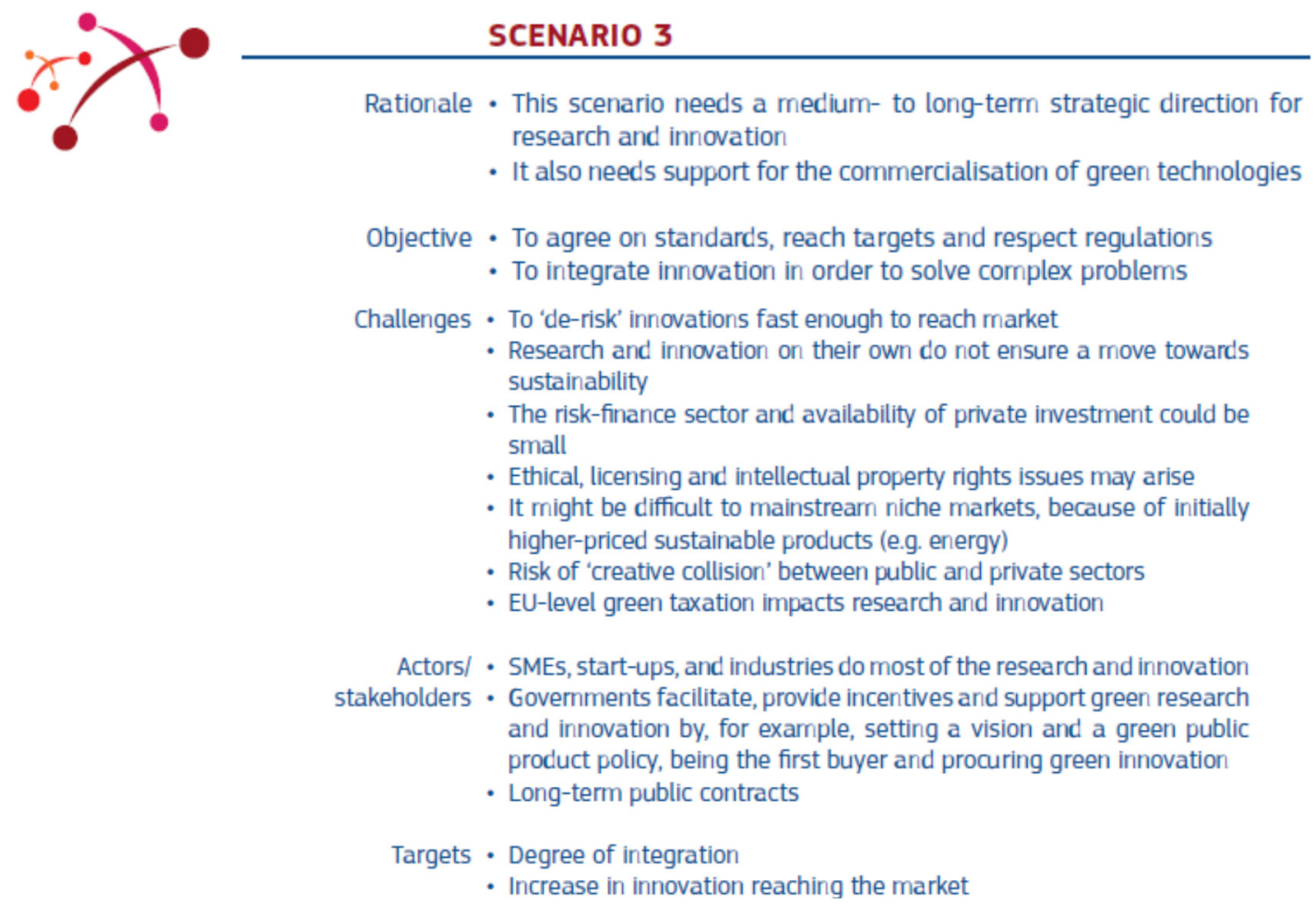

Figure 6. Example of a worked out policy area (Research and Innovation in Scenario 3).

\section{From General Policy Recommendations to Concrete Actions by All Stakeholders}

After some reflection, the study team came up with the idea of attracting people unfamiliar with the foresight exercise into the scenarios to enable them to develop their own thinking from within. It then engaged in the development of a scenario-based simulation system using serious gaming techniques. The purpose of this initiative was to develop a tool to enable people who were not associated to the study to derive policy and strategic insights directly relevant for them from the broad scenarios and policy reflections generated by the study.

After four months of co-development with professional gaming experts, the "JRC Scenario Exploration System" (SES) was ready. On the basis of a set of imaginary events leading to the scenarios, the SES makes participants act to reach self-defined long-term objectives and interact with each other. This is achieved by giving participants roles as policy-makers, businesses, and civil society organizations. The dynamics introduced in the simulation on the basis of the scenario time horizons make it possible to bring the alternative worlds described in the scenarios to life. The freedom to select the role each participant wants to take and to define numerous details allows the participants to personalize the experience. Further, carefully selecting an overarching theme for each session in agreement with the participants makes it possible to maximize the relevance of the simulation session for their own cases and perspectives. This approach can be used to bring further specificity to the work described above on the development of scenario-specific policy actions. It can also allow the possible impacts of selected policy packages to be tested by simulating what would happen in various scenarios. More information on the JRC SES is available [10]. A detailed description of the SES and its development has been published in the Journal of Future Studies [11]. 
These are still early days, but the SES has already been used successfully to explore how policy making at EU level in the area of food safety could evolve to preserve a high level of food safety for the long term while continuing to enable food innovation.

\section{Conclusions}

Managing a transition towards a sustainable economy and society is a complex endeavor requiring a future oriented systemic approach that looks at the EU economy and society as a whole, and goes beyond current agendas and policies. The objective of this work was to make a practical contribution to this challenge and to generate empirical evidence on the use of scenarios to that end. In spite of the long and widespread use of the scenario planning method [12], the authors are not aware of other attempts to use the method for policy making in the way described here. The JRC foresight study "2035: Paths towards a sustainable EU economy" developed four scenarios to explore how a sustainable transition could be possible. These scenarios are organized in a matrix around the fiscal framework ("green" or not) and societal values (individualistic or collaborative).

A large number of drivers of change were taken into account in the analysis of the future to construct scenarios of a sufficient depth and detail to generate a systemic understanding of four different possible and plausible future worlds. On that basis, the participants in the study identified which policy mixes would be best adapted to push each scenario towards a more sustainable future, while respecting its own logic and constraints.

For each scenario, 6 policy domains ( 7 for Scenario 4 ) considered the most relevant were selected among more than 50. Each was developed according to a common template: rationale for policy action; policy objectives; challenges faced; concerned actors and stakeholders; and possible policy targets. Research and innovation, new business models, and education were considered important for all four scenarios. The other domains were natural resources management, regulation, ethics, employment, transparency, governance, social protection, and systems integration.

Two main general lessons can be drawn from the approach. In the cases where the same policy area was applied to different scenarios, the scenarios allowed the study participants to develop rationales and objectives for policy action that are scenario-specific. This shows the usefulness of scenarios to provide meaningful background and context to develop concrete conversations on policies.

Conversely, putting the discussions on a broad range of policy areas into the perspective of one specific scenario ensured a strong level of coherence across them all. The systemic thinking generated by the scenario allowed to break silo thinking and made it possible to talk truly of "policy packages" development.

The study and the policy reflections that it generated, contrasting alternative scenarios when thinking about the transition to a more sustainable future, illustrates how powerful a policy framework which is fiscally supportive of environmental sustainability can be in supporting resource efficiency. The contrasting scenarios also allowed us to imagine how this can be achieved in very different ways depending on the prevailing social values. It also shows how a combination of actions in the absence of a favorable fiscal framework can be used to drive sustainability further. In sum, this work illustrates how the creative use of policy mixes can open the way to very different paths towards a sustainable future.

Once all this has been done, this approach allows us to take a step back and to look across scenarios to identify whether some policy options apply to all. If this is the case, and as the scenarios have been constructed to differ on some key aspects, these policy options can be considered 'no regret' options. In other words, these policies should be applied in any case as they contribute to reaching the overall policy objective across widely different framing conditions, regardless of the path towards the future that is being taken. For the policy options that are only meaningful in certain scenarios, it might be interesting to develop indicators that could be used to monitor how the situation is evolving and to decide on thresholds for these indicators to trigger the implementation of these policies. 
As the purpose of this study was to test a new way to use scenarios, the exercise remained at the level of the "basic policy packages." If the exercise were to be performed "for real," it would be possible to continue the reflection and pursue the analysis to look in detail at possible contradictions and unintended effects of the policies identified and at the political feasibility of what can be proposed.

However, in view of the generic nature of the scenarios and of the broad question to address, there was a limit to the level of specificity that could be reached by this exercise. In addition, while the exercise made sense to the participants in the study because they had reached a high level of common understanding through the foresight process, communicating on the logic developed in the study to people who are not familiar with it could be a challenge. Developing a serious gaming platform was one way to address this issue.

It would be very valuable to be able to repeat the process in the frame of an actual policy initiative with the involvement of the policy-makers in charge, with an objective of effective implementation of the results obtained.

Acknowledgments: Our thanks go to Aaron Rosa, from the Hawaii Research Center for Futures Studies, Honolulu, and John A. Sweeney, from the Center for Postnormal Policy and Futures Studies, Chicago, for their support in developing the JRC Scenario Exploration System.

Author Contributions: Laurent Bontoux conceived, designed, and ran the foresight study at the basis of this paper and wrote the bulk of the contribution. Daniel Bengtsson provided essential help and intellectual input along the whole study and game development process.

Conflicts of Interest: The authors declare no conflict of interest.

\section{Abbreviations}

The following abbreviations are used in this manuscript:

JRC Joint Research Centre

SES Scenario Exploration System

\section{References}

1. Cuhls, K. Lessons for Policy-Making from Foresight in Non-European Countries, Policy Paper by the Research, Innovation, and Science Policy Experts (RISE) High Level Group, European Commission Directorate-General for Research and Innovation. Available online: https://ec.europa.eu/research/ innovation-union/pdf/expert-groups/rise/cuhls-lessons_policy_making.pdf (accessed on 11 March 2016).

2. Markard, J.; Raven, R.; Truffer, B. Sustainability transitions: An emerging field of research and its prospects. Res. Policy 2012, 41, 955-967. [CrossRef]

3. Bontoux, L.; Bengtsson, D. 2035: Paths towards a Sustainable EU Economy Sustainable Transitions and the Potential of Eco-Innovation for Jobs and Economic Development in EU Eco-Industries 2035. JRC Science for Policy Report, Foresight Series, EUR 27376 EN. 2015. Available online: https:/ /ec.europa.eu/ $\mathrm{jrc/en/publication/eur-scientific-and-technical-research-reports/2035-paths-towards-sustainable-eu-economy-}$ sustainable-transitions-and-potential-eco (accessed on 11 March 2016).

4. Backhaus, J.; Breukers, S.; Mont, O.; Paukovic, M.; Mourik, R. Sustainable Lifestyles: Today's Facts \& Tomorrow's Trends, SPREAD Sustainable Lifestyles 2050 Project Deliverable D1.1 Sustainable Lifestyles Baseline Report. 2013. Available online: http://www.sustainable-lifestyles.eu/fileadmin/images/ content/D1.1_Baseline_Report.pdf (accessed on 25 January 2016).

5. Dictionnaire Larousse. Available online: http://www.larousse.fr/dictionnaires/francais/\%C3\%A9coindustrie_\%C3\%A9co-industries/27603 (accessed on 25 January 2016).

6. ECORYS. Study on the Competitiveness of the EU eco-industry, Part 2. 2009. Available online: http://ec.europa.eu/environment/enveco/eco_industry/pdf/report\%20_2009_competitiveness_part2.pdf (accessed on 11 March 2016).

7. FOR-LEARN Online Guide. Scenario Building Methodology. Available online: http://forlearn.jrc.ec. europa.eu/guide/4_methodology/meth_scenario.htm (accessed on 25 January 2016). 
8. Eran, F.; Moshe, G.; Elah, M. Policy Packaging and Its Applicability to Servicizing-A Summary of a Concept, SPREE Project Deliverable n`2.1. Available online: http://www.spreeproject.com/wp-content/ uploads/2013/04/Deliverable-2.1_website.pdf (accessed on 25 January 2016).

9. Bontoux, L.; Bengtsson, D. 2035: Paths towards a Sustainable EU Economy Sustainable Transitions and the Potential of Eco-Innovation for Jobs and Economic Development in EU Eco-Industries 2035, brochure summarizing the JRC Science for Policy report, KJ-04-15-924-EN-C. Available online: https:/ /ec.europa.eu/jrc/sites/default/files/jrc-towards-sustainable-economy-2035-brochure_en.pdf (accessed on 24 March 2016).

10. JRC Science Hub. Description of the Scenario Exploration System. Available online: https://ec.europa.eu/ $\mathrm{jrc} / \mathrm{en} /$ research/foresight/ses (accessed on 24 March 2016).

11. Bontoux, L.; Bengtsson, D.; Rosa, A.; Sweeney, J.A. The JRC Scenario Exploration System: From Study to Serious Game. J. Futures Stud. 2016, 20, 3-20.

12. FOR-LEARN Online Guide. Historical Notes on the Scenario Building Methodology. Available online: http://forlearn.jrc.ec.europa.eu/guide/4_methodology/meth_scenario.htm\#History (accessed on 24 March 2016).

(C) 2016 by the authors; licensee MDPI, Basel, Switzerland. This article is an open access article distributed under the terms and conditions of the Creative Commons by Attribution (CC-BY) license (http:/ / creativecommons.org/licenses/by/4.0/). 